\title{
REGEPE

https://doi.org/10.14211/regepe.v8i3.1375

\section{PROPOSTA DE MODELO DE GESTÃO FINANCEIRA APLICADA A UMA EMPRESA DE PEQUENO PORTE NO SEGMENTO DE FERTILIZANTES}

Recebido: 07/01/2019
Aprovado: 19/07/2019

\author{
${ }^{1}$ André Leme de Moura \\ 2 David Ferreira Lopes Santos \\ ${ }^{3}$ Elimar Veloso Conceição
}

Objetivo: Trata-se de uma pesquisa aplicada com vistas a propor um modelo de gestão financeira aplicada a uma empresa do segmento de fertilizantes agrícolas, capaz de estruturar todas as informações financeiras da empresa com o objetivo de subsidiar o processo de gestão e a tomada de decisão.

Método: Realizou-se uma pesquisa quanti-qualitativa baseada em técnicas de observação participante e pesquisa-ação em uma empresa específica do setor de fertilizantes agrícolas. Os materiais foram coletados junto a fontes primárias (observação e entrevistas) da empresa e secundárias (documentos da empresa e informações financeiras do setor).

Originalidade/Relevância: $O$ contexto apresentado expõe uma lacuna teórico-aplicada de instrumentos que auxiliam em "como" construir e estruturar as informações financeiras para as PMEs de forma exequível ao empresário ou gestor que não possui uma formação educacional nessa área.

Resultados: Os resultados deste estudo viabilizam a criação de um modelo empírico de gestão financeira que: i) demonstra desde a estrutura organizacional necessária; ii) os processos operacionais inerentes à atividade; e iii) os indicadores que devem ser utilizados para a análise da situação financeira e a tomada de decisão.

Contribuições teóricas/metodológicas: Essas evidências podem servir como parâmetro ou insights para outras empresas do segmento de fertilizantes e demais empresas de pequeno porte, além de pesquisadores no âmbito organizacional.

Palavras-chave: Administração Financeira; Diagnóstico Empresarial; Indicadores Financeiros; Painel de Desempenho; Processo de Gestão.

\footnotetext{
1 Universidade Estadual Paulista - UNESP, São Paulo (Brasil). E-mail: moura.andre@me.com Orcid id: https://orcid.org/0000-0001-9666-0166

2 Universidade Estadual Paulista - UNESP, São Paulo (Brasil). E-mail: david.lopes@unesp.br Orcid id: https://orcid.org/0000-0003-3890-6417

${ }^{3}$ Industria e Com. de Auto Peças Rei Ltda, São Paulo (Brasil). E-mail: eli fisica@hotmail.com Orcid id: http://orcid.org/0000-0003-0089-0448
} 


\section{PROPOSED MODEL OF FINANCIAL MANAGEMENT APPLIED TO A SMALL BUSINESS COMPANY IN THE SEGMENT OF FERTILIZERS}

Objective: This is an applied research aimed at proposing a model of financial management applied to a company in the segment of agricultural fertilizers, able to structure all the financial information of the company with the objective of subsidizing the management process and the taking of decisionmaking.

Method: A quantitative-qualitative method was conducted based on participant observation and action research techniques in a company specific to the agricultural fertilizer sector. The materials were collected together with primary sources (observation and interviews) of the company and secondary (company documents and financial information of the sector).

Originality/Relevance: The presented context exposes a theoretical-applied gap of instruments that help in "how" to construct and structure the financial information for SMEs in a feasible way to the entrepreneur or manager who does not have an educational formation in this area.

Results: The results of this study make possible the creation of an empirical model of financial management that: i) demonstrates from the organizational structure required; ii) the operational processes inherent to the activity; and iii) the indicators that should be used for the analysis of the financial situation and the decision making.

Theoretical/methodological contributions: These evidences can serve as parameters or insights for other companies of the segment of fertilizers and other small companies, as well as researchers in the organizational scope.

Keywords: Financial Management; Business Diagnostics; Financial Indicators; Performance Panel; Management Process.

\section{PROPUESTA DE MODELO DE GESTIÓN FINANCIERA APLICADA A UNA EMPRESA DE PEQUEÑO PORTE EN EL SEGMENTO DE FERTILIZANTES}

Objetivo: Esta és una investigación aplicada con vistas a proponer un modelo de gestión financiera, aplicada a una empresa del segmento de fertilizantes agrícolas, capaz de estructurar toda la información financiera de la empresa con el objetivo de subsidiar el proceso de gestión y la toma de decisión.

Método: Se realizó una investigación cuantitativa cualitativa basada en técnicas de observación participante e investigación-acción en una empresa específica del sector de fertilizantes agrícolas. Los materiales fueron recolectados junto a fuentes primarias (observación y entrevistas) de la empresa y secundarias (documentos de la empresa e informaciones financieras del sector).

Originalidad/Relevancia: El contexto presentado expone una laguna teórico-aplicada de instrumentos que auxilian en "cómo" construir y estructurar las informaciones financieras para las PYME de forma viable al empresario o gestor que no posee una formación educativa en esa área.

Resultados: Los resultados de este estudio posibilitan la creación de un modelo empírico de gestión financiera que: i) demuestra desde la estructura organizativa necesaria; ii) los procesos operativos inherentes a la actividad; iii) los indicadores que deben utilizarse para el análisis de la situación financiera y la toma de decisiones.

Contribuciones teóricas / metodológicas: Estas evidencias pueden servir como parámetro y conocimientos para otras empresas del segmento de fertilizantes y demás empresas de pequeño porte, además de investigadores en el ámbito organizacional.

Palabras clave: Administración Financiera; Diagnóstico Empresarial; Indicadores Financieros; Panel de Rendimiento; Proceso de Gestión. 


\section{INTRODUÇÃO}

Sabe-se que a longevidade das pequenas e médias empresas (PMEs) brasileiras é inferior a 5 anos para mais de $80 \%$ das empresas nascentes (Conceição, Saraiva, Fochezatto, \& Aniceto França, 2018; SEBRAE, 2016). Não obstante, para aquelas que se mantêm no mercado, são poucas as que conseguem lograr uma taxa de crescimento ou de reinvestimento de capital que permite o seu desenvolvimento a médio e longo prazo (Serrasqueiro, Leitão, \& Smallbone, 2018).

Uma das causas centrais desse problema é a ausência ou a fraca formalização de seus processos gerenciais (Santini, Favarin, Nogueira, Oliveira, \& Ruppenthal, 2015). É notável que diferentes estudos acadêmicos e de mercado reportem que uma pequena fração dos pequenos e médios empresários conheçam, de fato, a situação financeira de suas empresas e saibam como analisar e criar estratégias para resolver problemas ou potencializar oportunidades (Escrivão Filho, Albuquerque, Nagano, Philippsen Junior, \& Oliveira, 2017).

A literatura relativa às finanças corporativas tem o seu mainstream formado $e$ desenvolvido no lastro de grandes corporações (Vilarinho, Lopes, \& Sousa, 2018) que apresentam sistemas contábeis-financeiros estruturados, auditados e publicados (Rahman, Belas, Kliestik, \& Tyll, 2017). Não obstante, esses estudos empíricos são orientados a entender quais decisões são tomadas, suas causas e reflexos a partir de uma estrutura de informação padrão e comparável (Lousada, \& Valentim, 2011).

Por outro lado, ao voltar-se para as PMEs, trabalhos como o de Hall, Costa, Kreuzberg, Moura e Hein (2012), Moreira, Encarnação, Bispo, Angotti e Colauto (2013) e Vilas Boas e Morais (2014) apresentam as limitações das informações contábeis aplicadas às PMEs. Vogel e Wood Jr. (2013) e Formenti e Martins (2015) destacam que o Pequeno e Médio Empresário têm consciência da necessidade da implementação dos indicadores financeiros, mas isto nem sempre ocorre na prática. Trabalhos como o de Panucci-Filho e Cherobin (2011), Pimenta e Silva (2017) e Jones e Jacinto (2013) apresentam aplicações empíricas de modelos que analisam os instrumentos financeiros em PMEs, destacando sua importância para o processo de gestão. 
O contexto apresentado expõe uma lacuna teórico-aplicada de instrumentos que auxiliam em "como" construir e estruturar as informações financeiras para as PMEs de forma exequível ao empresário ou gestor que não possui uma formação educacional nessa área. Não se trata, portanto, do desenvolvimento de novas teorias, mas de como aplicar ou tornar mais acessível às PMEs o arcabouço teórico existente na literatura das finanças corporativas para auxiliar gestores e/ou proprietários das PMEs a gerenciar as finanças de suas empresas.

A importância do "como" fazer pode ser entendida de forma análoga ao que ocorre nas Ciências Jurídicas, em que, além das bases teóricas dos diferentes direitos (trabalhista, tributário, penal, civil, empresarial, entre outros), há uma estrutura teórica sobre o "processo" de cada um desses direitos, isto é, existe um campo de conhecimento instrumental e ordenado para formalizar a operacionalização do direito (Almeida, 2018).

Cumpre à academia não apenas a proposição do que deve ser feito, mas também a instrumentalização teórica em ações gerenciais que sejam simples e efetivas (Meyer Junior, Pascucci, \& Murphy, 2012). Assim, este artigo tem como escopo propor um modelo de gestão financeira aplicada a uma PME que atua no segmento de fertilizantes agrícolas.

Ainda que estudos de caso não permitam a generalização do fenômeno estudado (Yin, 2015), essa estratégia metodológica permite maior interação com o objeto investigado (empresa) de modo a externar o seu contexto e discutir de maneira empírica os resultados. Essa estratégia metodológica tem a valia de possibilitar reflexões para outras empresas de porte semelhante para este ou segmentos empresariais distintos (Nadin, \& Cassell, 2006).

No Brasil, existem mais de 18 milhões de empresas (pessoas jurídicas), das quais mais de 95\% são PMEs, conforme a Receita Federal do Brasil. As PMEs respondem por $27 \%$ do PIB nacional e $52 \%$ dos empregos no país (SEBRAE, 2016). Diante disso, ações que contribuem para a longevidade e sustentabilidade desse tipo de organização produtiva vão ao encontro do desenvolvimento econômico do país.

É instigante que a representatividade econômica e social das PMEs não as torne o principal objeto de estudo das finanças corporativas. Entretanto, consolida-se na prática que $88 \%$ das empresas terceirizam seu processo de contabilidade (Vilas 
Boas, \& Morais, 2014). Os demonstrativos são tratados como mera obrigação fiscal (Moreira et al., 2013) e muitas empresas utilizam índices elaborados sem os padrões e rigores postulados pela contabilidade (Hall et al., 2012).

É possível que a dificuldade de acesso às informações financeiras apresentadas pelos acadêmicos, bem como a baixa formalização, padronização e confiabilidade, em função da falta de uma estruturação contábil robusta, sejam empecilhos à proposição de pesquisas. Adicionalmente, o esforço acadêmico em entregar "representatividade" e "validade" de resultados pode direcionar investigações para um número mais amplo de empresas, por isso o maior foco em grandes organizações.

Diante desse cenário, esta pesquisa foi desenvolvida a partir do questionamento do próprio empresário da empresa investigada: Como devo organizar e gerenciar a área financeira de minha empresa? Apesar da simplicidade da pergunta, é desafiador encontrar a resposta de forma pragmática em quaisquer dos manuais clássicos de finanças corporativas, sejam nacionais ou internacionais.

A partir de uma pesquisa quanti-qualitativa baseada em técnicas de observação participante e pesquisa-ação, tem como objetivo geral propor um modelo de gestão financeira, aplicada a uma empresa do segmento de fertilizantes agrícolas, capaz de estruturar todas as informações financeiras da empresa com o objetivo de subsidiar o processo de gestão e a tomada de decisão.

Como objetivos intermediários, têm-se: i) demonstrar desde a estrutura organizacional necessária; ii) os processos operacionais inerentes à atividade; e iii) os indicadores que devem ser utilizados para a análise da situação financeira e a tomada de decisão.

O segmento de fertilizantes ou nutrição vegetal está integrado à cadeia de valor do agronegócio, sendo o principal fornecedor de insumos para a produção agrícola do Brasil (Barros, \& Silva, 2008). A indústria de nutrição vegetal é composta por empresas fabricantes de produtos nos segmentos de fertilizantes foliares, biofertilizantes, fertilizantes orgânicos, organominerais, condicionadores de solo, mineralizadores e substratos para planta (Abisolo, 2016).

O faturamento da indústria de nutrição vegetal totalizou $R$ \$ 5,2 bilhões em 2015, um crescimento de $13 \%$ em relação ao ano anterior, frente a uma retração econômica apresentada pela economia brasileira no mesmo período. Em adição, Rev. Empreendedorismo Gest. Pequenas Empres. | São Paulo, v.8 | n.3 | p. 36-68 | Set/Dez. 2019. 
destaca-se sua importância social, empregando 14,4 mil funcionários em 2015 (Abisolo, 2016).

Esse mercado contabilizou 414 empresas registradas e ativas no ano de 2015, sendo composto predominantemente por micro e pequenas empresas, representando 73,7\% do total de empresas de nutrição vegetal (Abisolo, 2016)

Apesar da representatividade das PMEs no setor de fertilizantes, observa-se um processo de concentração de mercado com a formação de grupos econômicos cada vez maiores (Barbalho Júnior, \& Callado, 2008). Como o setor é diretamente dependente de produtos e insumos importados (Dias, \& Fernandes, 2006), a competitividade, a dinâmica cambial, regulatória e de comércio exterior requerem das empresas processos gerenciais dinâmicos, ágeis e efetivos (Reis, Fernandes, \& Nakata, 2018).

Diante disso, a escolha da empresa ora em estudo representa um setor relevante para o país em diferentes dimensões, sendo pouco explorado nos estudos organizacionais, por isso, os resultados aqui construídos podem contribuir com a literatura voltada para PMEs, especialmente em como operacionalizar a gestão financeira das empresas. Adicionalmente, traz contribuições gerenciais específicas para PMEs que eventualmente possam auxiliar na longevidade destas organizações.

Para melhor organizar o estudo, este artigo foi estruturado em cinco seções. Além desta seção inicial, serão tratados os fundamentos teóricos relativos às decisões financeiras, os procedimentos metodológicos, os resultados da pesquisa com a proposição do modelo de gestão financeira e as considerações finais. As referências encerram o estudo.

\section{REFERENCIAL TEÓRICO}

A administração financeira é um elemento indispensável ao processo administrativo. Ross, Westerfield e Jaffe (2002) afirmam que a função da administração financeira é criar valor nas atividades de investimento, financiamento e gestão de liquidez da empresa. 


\subsection{Estrutura Organizacional}

Segundo Mintzberg (2003), a estrutura organizacional pode ser definida como a maneira pela qual o trabalho é dividido em tarefas distintas e, posteriormente, como é realizada a coordenação entre essas tarefas. De acordo com o autor, uma estrutura organizacional é baseada, essencialmente, na maneira como a autoridade é distribuída na organização.

As PMEs, quando devidamente estruturadas, têm uma estrutura organizacional enxuta (Gonzalez-Loureiro, Sousa, \& Pinto, 2017) e um processo mais curto de tomada de decisões, permitindo um fluxo de informações mais rápido e com melhor qualidade de comunicação (Reis et al., 2018). Essas característiscas são necessárias para manter a sobrevivência no setor de fertilizantes, que é caracterizado por forte concorrência de grandes empresas e que sofre elevada influência de variáveis macroeconômicas (variação cambial, damanda de fertilizantes, preço das commodities agrícolas) (Barbalho Júnior, \& Callado, 2008; Dias, \& Fernandes, 2006).

\subsection{Processos e Atividades Financeiras}

Gitman (1997) e Assaf Neto (2014) apresentaram as atividades-chave da administração financeira: i) análise e planejamento financeiro; ii) decisões de investimento; e iii) decisões de financiamento.

A análise e o planejamento financeiro têm como objetivo fundamental avaliar e desenvolver o fluxo de caixa da empresa, garantindo os recursos necessários para o alcance dos objetivos (Gitman, 1997), evidenciando as necessidades de expansão e eventuais desastres futuros (Assaf Neto, 2014), assim como estabelecer métodos pelos quais as metas financeiras devem ser atingidas (Ross et al., 2002).

Em relação às decisões de investimento, Gitman (1997) e Assaf Neto (2014) afirmam que elas determinam a combinação e o tipo de ativos constantes do balanço patrimonial da empresa, isto é, ao montante de recursos aplicados em ativos circulantes e permanentes e também à escolha de quais ativos adquirir, e quando devem ser substituídos, modificados ou liquidados. 
As decisões de financiamento, por sua vez, referem-se às combinações e às fontes individuais mais adequadas para estes financiamentos, considerando o curto e o longo prazo (Gitman, 1997; Assaf Neto, 2014).

Sendo assim, esta seção tem como objetivo fornecer ferramentas para realizar com êxito a análise e o planejamento financeiro e também para as decisões de investimento e de financiamento.

\subsubsection{Análise e planejamento financeiro}

Uma administração ineficiente do capital de giro reflete negativamente no fluxo de caixa da organização (Zouain, Ferreira, Macedo, Sant'Anna, Longo, \& Barone, 2011) e tem grande representatividade nos fatores de mortalidade das PMEs (Santini et al., 2015). Carvalho (2015) destacou a importância do capital de giro para o desempenho das empresas, uma vez que grande parte do capital das PMEs está investido em ativos circulantes (recebíveis, estoques e caixa).

A administração do capital de giro compreende um conjunto de decisões que visa garantir a adequada consecução das políticas da empresa, direcionando e otimizando a parcela de capital aplicada em seu ciclo operacional (Assaf Neto, 2014). Para definir um volume adequado (ótimo) de capital de giro, devem ser obedecidas as particularidades operacionais da empresa e de seu ambiente, visando maximizar seu retorno e minimizar seu risco (Assaf Neto, 2014). Esta necessidade fica evidenciada no segmento de fertilizantes, uma vez que a demanda no país, principalmente em relação à soja e ao milho reproduz no setor a volatilidade do preço internacional dessas commodities (Barbalho Júnior, \& Callado, 2008).

A definição do nível adequado torna-se mais complexo em ambientes sujeitos a fatores sazonais. Zouain et al. (2011) observam que a sazonalidade impõe desafios aos administradores financeiros, implicando em maiores níveis de estoques e de duplicatas a receber, uma vez que as receitas serão concentradas em épocas específicas do ano. Barbalho Júnior e Callado (2008) comentam que a sazonalidade no consumo de fertilizante leva a existência de capacidade ociosa durante parte do ano, aumentando os custos de estoque e matéria-prima.

Diante disso, destaca-se a importância do orçamento de caixa. Maduekwe e Kamala (2016) afirmam que os orçamentos são frequentemente utilizados para 
monitoramento dos negócios, medição de performance, planejamento futuro e melhora no processo de tomada de decisões.

A estagnação sazonal do setor afeta negativamente o endividamento de curto prazo da empresa (Erdogan, 2018). Diante disso, a gestão de recebíveis é particularmente importante para PMEs, uma vez que representam grande parcela de seus investimentos (Martínez-Sola, García-Teruel, \& Martínez-Solano, 2014), promovem as vendas e financiam o capital de giro (Lin, \& Chou, 2015).

Atnafu e Balda (2018) demonstraram que um elevado nível de gerenciamento de estoque aumenta as vantagens competitivas das PMEs, melhorando 0 desempenho. Pillai (2014) destacou que, apesar da reconhecida importância da gestão do estoque, na prática, as decisões de boa parte das PMEs são baseadas apenas na intuição.

A gestão do estoque, para Ivanovich e Viktorovna (2016), envolve tanto os objetivos operacionais como os estratégicos de uma empresa. Para um planejamento eficiente de estoques é necessária uma boa previsão de produção e vendas. Assim, é importante colocar foco em ferramentas reconhecidas para a previsão, reabastecimento e manuseio geral do estoque (Ngubane, Mayekiso, Sikota, Fitshane, Matsoso, \& Bruwer, 2015).

A classificação $A B C$ é um método reconhecido de classificação de estoque. Com base no princípio de Pareto, classificam-se os estoques em três grupos de acordo com o investimento requerido. No grupo A, estão $20 \%$ de todos os itens, que representam $80 \%$ do valor total investido em estoques. No grupo B, estão $30 \%$ de todos os itens, representando, aproximadamente, $15 \%$ do valor total investido em estoque. Os demais itens estão no grupo C, representando, aproximadamente, 5\% do montante investido (Iqbal, Malzahn, \& Whitman, 2017).

\subsubsection{Decisões de investimento}

As decisões de investimento são consideradas as mais importantes a serem tomadas pelas empresas. Envolvem todo o processo de identificação, avaliação e seleção das alternativas de aplicações de recursos na expectativa de promoverem benefícios econômicos futuros (Assaf Neto, 2014). 
Existem métodos para analisar economicamente as alternativas de investimento. Classicamente, destacam-se três (Chittenden, \& Derregia, 2015):

I. Períodos de Payback;

II. Valor Presente Líquido (VPL);

III. Taxa Interna de Retorno (TIR).

O método de períodos de Payback corresponde ao tempo necessário para que as entradas de caixa de um projeto se igualem ao seu investimento inicial (Assaf Neto, 2014).

O Valor Presente Líquido é considerado uma técnica sofisticada de análise de investimentos e é calculado por meio do fluxo de caixa descontado pela taxa de juros requerida para o investimento. Para que um projeto seja aceito, seu VPL deve ser maior ou igual a zero (Assaf Neto, 2014).

A TIR corresponde à taxa de desconto em que o VPL se iguala a zero (Patrick, \& French, 2016). Se o valor encontrado for superior ao custo de oportunidade desejado, aceita-se a proposta de investimento (Copiello, 2016).

\subsubsection{Decisões de financiamento}

O custo de capital é de fundamental importância, tanto para as decisões de investimento quanto para as de financiamento (Nascimento, 2013), sendo composto pelo custo do capital próprio ( $\left.\mathrm{K}_{\mathrm{e}}\right)$ e o custo da dívida ( $\left.\mathrm{K}_{\mathrm{d}}\right)$ (Assaf Neto, 2014).

$\mathrm{O}\left(\mathrm{K}_{\mathrm{e}}\right)$ pode ser calculado com a utilização do modelo de precificação de ativos (CAPM). Esse modelo estabelece uma relação linear entre o retorno de um ativo e o retorno de mercado estabelecendo um retorno que compense o risco assumido (Assaf Neto, 2014).

$\mathrm{O}\left(\mathrm{K}_{\mathrm{d}}\right)$ pode ser definido de acordo com os passivos onerosos da empresa identificados nos empréstimos e financiamentos. O custo de capital de terceiros possui dedutibilidade fiscal dos encargos financeiros (Assaf Neto, 2014), caso a empresa seja tributada pelo lucro real, o que não é frequente nas PMEs (Paula, Costa, \& Ferreira, 2017).

Após o cálculo dos custos de cada fonte de financiamento, é fundamental determinar o custo total de capital, também conhecido com taxa de atratividade. Para o cálculo do custo total de capital, utiliza-se a fórmula 01 que traz o custo 
médio ponderado de capital (CMPC) ou Weighted Average Cost of Capital (WACC), (Assaf Neto, 2014):

$W A C C=W_{J} \times K_{i}+W_{J} \times K_{e}$

onde:

$\mathrm{Ki}=$ custo do capital de terceiros;

$\mathrm{Ke}=$ custo do capital próprio;

WJ = participação relativa (proporção) de cada fonte de capital no financiamento total.

\subsection{Indicadores/Painel de Desempenho}

Para avaliar o crescimento e prever a possibilidade de falência em pequenas empresas é fundamental a utilização dos indicadores financeiros (Lukason, Laitinen, \& Suvas 2015). Leoneti, Nirazawa e Oliveira (2016), Vogel e Wood Jr. (2013) apresentam as dificuldades encontradas pelas PMEs ao utilizarem indicadores de desempenho tradicionais, destacando fatores como ausência de planejamento estratégico, problemas organizacionais e ausência de um sistema de gestão eficiente.

Maté-Sánchez-Val, López-Hernandez e Mur-Lacambra (2017) destacam que as PMEs com indicadores financeiros longe de seus benchmarks incorrem em custos por estarem fora do equilíbrio. Com isso, os gestores devem realizar as mudanças de modo a equalizá-las.

Existem diversos indicadores úteis para avaliar a situação de uma empresa. Esses indicadores podem ser classificados em quatro grupos: liquidez, atividade, endividamento e estrutura e rentabilidade (Assaf Neto, 2014). Na prática, pretendese avaliar os reflexos das decisões tomadas por uma empresa sobre sua liquidez, estrutura patrimonial e rentabilidade (Assaf Neto, 2014).

A literatura acerca da administração financeira é escassa quanto à aplicação de indicadores ou modelos relacionados com PMEs, o que pode ser proveniente das limitações contábeis apresentadas por Hall et al. (2012), Moreira et al. (2013), Vilas 
Boas e Morais (2014). Alguns dos indicadores apresentados por Santos (2015), Lukason et al. (2015), Assaf Neto (2014) e Martins, Goes, Shikida, Gimenes, \& Piacenti (2015) aplicáveis a uma empresa de médio porte são apresentados na Figura 1:

\begin{tabular}{|c|c|c|c|c|}
\hline Tipo & Indicador & Fórmula & Objetivo & Autor \\
\hline \multirow{3}{*}{$\begin{array}{l}\frac{0}{0} \\
\frac{\pi}{0} \\
\frac{0}{\overline{0}} \\
\frac{\pi}{\pi} \\
\stackrel{0}{0} \\
\simeq\end{array}$} & $\begin{array}{c}\text { Retorno } \\
\text { Residual (RR) }\end{array}$ & $R R=R O I-C M P C$ & $\begin{array}{l}\text { Identificar o spread das } \\
\text { operações da empresa } \\
\text { frente o custo ponderado } \\
\text { de captação de recursos. }\end{array}$ & $\begin{array}{l}\text { Assaf } \\
\text { Neto } \\
(2014)\end{array}$ \\
\hline & $\begin{array}{l}\text { Retorno sobre } \\
\text { Investimento } \\
\quad(\mathrm{ROI})\end{array}$ & $R O I=\frac{\text { Lucro Operacional Líquido }}{\text { Investimento }} \times 100$ & $\begin{array}{l}\text { Mensurar a taxa de } \\
\text { retorno dos investimentos } \\
\text { da empresa. }\end{array}$ & $\begin{array}{l}\text { Martins } \\
\text { et al. } \\
\text { (2015) }\end{array}$ \\
\hline & $\begin{array}{l}\text { Retorno sobre } \\
\text { Patrimônio } \\
\text { (ROE) }\end{array}$ & ROE $=\frac{\text { Lucro Líquido }}{\text { Patrimônio Líquido Médio }} \times 100$ & $\begin{array}{l}\text { Mensurar a taxa de } \\
\text { retorno alcançada pelos } \\
\text { sócios da empresa. }\end{array}$ & $\begin{array}{l}\text { Lukason } \\
\text { et al. } \\
\text { (2015) }\end{array}$ \\
\hline \multirow{3}{*}{ 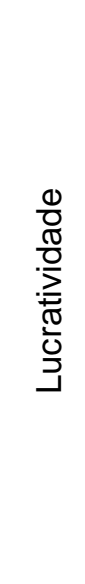 } & $\begin{array}{l}\text { Margem Bruta } \\
\text { (MB) }\end{array}$ & $M B=\frac{\text { Lucro Bruto }}{\text { Receita Líquida }} \times 100$ & $\begin{array}{l}\text { Identificar o ganho da } \\
\text { empresa em relação as } \\
\text { atividades operacionais. }\end{array}$ & $\begin{array}{l}\text { Santos } \\
(2015)\end{array}$ \\
\hline & $\begin{array}{l}\text { Margem } \\
\text { Operacional } \\
\text { (MO) }\end{array}$ & $M O=\frac{E B I T}{\text { Receita Líquida }} \times 100$ & $\begin{array}{l}\text { Identificar o ganho da } \\
\text { empresa tendo como } \\
\text { base as atividades } \\
\text { operacionais, } \\
\text { administrativas e } \\
\text { comerciais. }\end{array}$ & $\begin{array}{l}\text { Santos } \\
(2015)\end{array}$ \\
\hline & $\begin{array}{c}\text { Margem } \\
\text { Líquida (ML) }\end{array}$ & $M L=\frac{\text { Lucro Líquido }}{\text { Receita Líquida }} \times 100$ & $\begin{array}{l}\text { Mensurar o ganho da } \\
\text { empresa relativo aos } \\
\text { sócios. }\end{array}$ & $\begin{array}{l}\text { Santos } \\
(2015)\end{array}$ \\
\hline \multirow{4}{*}{ 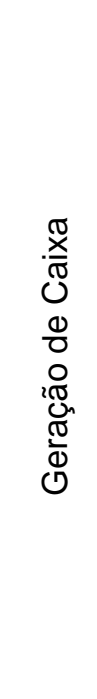 } & $\begin{array}{l}\text { Giro do Ativo } \\
\text { (GA) }\end{array}$ & $G A=\frac{\text { Vendas }}{\text { Ativos Totais }} \times 100$ & $\begin{array}{l}\text { Mensurar a produtividade } \\
\text { dos ativos totais em } \\
\text { relação às vendas. }\end{array}$ & $\begin{array}{l}\text { Lukason } \\
\text { et al. } \\
\text { (2015) }\end{array}$ \\
\hline & $\begin{array}{l}\text { Crescimento de } \\
\text { Receita (VR) }\end{array}$ & $V R=\frac{\left(\text { Receit }_{t}-\text { Receit }_{t-1}\right)}{\text { Receita }_{t-1}} \times 100$ & $\begin{array}{l}\text { Identificar a variação da } \\
\text { receita líquida da } \\
\text { empresa. }\end{array}$ & $\begin{array}{l}\text { Santos } \\
(2015)\end{array}$ \\
\hline & $\begin{array}{c}\text { Margem } \\
\text { EBTIDA (ME) }\end{array}$ & $M E=\frac{E B T I D A}{\text { Receita Líquida }}$ & $\begin{array}{l}\text { Mensurar o caixa gerado } \\
\text { pelas atividades da } \\
\text { empresa em relação à } \\
\text { receita líquida. }\end{array}$ & $\begin{array}{l}\text { Assaf } \\
\text { Neto } \\
(2014)\end{array}$ \\
\hline & $\begin{array}{l}\text { Capacidade de } \\
\text { Cobertura de } \\
\text { Juros (CCJ) }\end{array}$ & $C C J=\frac{E B I T}{\text { Despesas Financeiras }}$ & $\begin{array}{l}\text { Avaliar a disponibilidade } \\
\text { de recursos da empresa } \\
\text { em para a quitação das } \\
\text { despesas financeiras. }\end{array}$ & $\begin{array}{l}\text { Santos } \\
(2015)\end{array}$ \\
\hline
\end{tabular}


André Leme de Moura, David Ferreira Lopes Santos \& Elimar Veloso Conceição

\begin{tabular}{|c|c|c|c|c|}
\hline \multirow{3}{*}{ 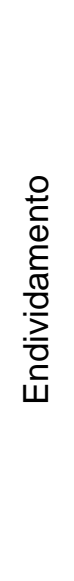 } & $\begin{array}{l}\text { Endividamento } \\
\text { Geral (EG) }\end{array}$ & $E G=\frac{\text { Dívida Bruta Total }}{\text { Ativo Total }}$ & $\begin{array}{l}\text { Identificar a composição } \\
\text { do ativo financiada por } \\
\text { passivo oneroso. }\end{array}$ & $\begin{array}{l}\text { Santos } \\
(2015)\end{array}$ \\
\hline & $\begin{array}{l}\text { Endividamento } \\
\text { a Curto Prazo } \\
\text { (ECP) }\end{array}$ & ECP $=\frac{\text { Dívida de Curto Prazo }}{\text { Dívida Bruta Total }}$ & $\begin{array}{l}\text { Avaliar a estrutura de } \\
\text { endividamento da } \\
\text { empresa quanto ao } \\
\text { tempo para liquidação da } \\
\text { obrigação. }\end{array}$ & $\begin{array}{l}\text { Santos } \\
(2015)\end{array}$ \\
\hline & $\begin{array}{l}\text { Coeficiente de } \\
\text { Efeito Tesoura } \\
\text { (CET) }\end{array}$ & $C E T=\frac{\text { Saldo de Tesouraria }}{\text { Receita Líquida }}$ & $\begin{array}{l}\text { Permite avaliar a } \\
\text { possibilidade de } \\
\text { ocorrência de efeito } \\
\text { tesoura (overtrading). }\end{array}$ & $\begin{array}{l}\text { Assaf } \\
\text { Neto } \\
(2014)\end{array}$ \\
\hline \multirow{6}{*}{$\begin{array}{l}\stackrel{N}{0} \\
\frac{0}{\bar{O}} \\
\frac{0}{3}\end{array}$} & $\begin{array}{l}\text { Liquidez } \\
\text { Corrente (LC) }\end{array}$ & $L C=\frac{\text { Ativo Circulante }}{\text { Passivo Circulante }}$ & $\begin{array}{l}\text { Avaliar a capacidade da } \\
\text { empresa em honrar suas } \\
\text { obrigações de curto } \\
\text { prazo. }\end{array}$ & $\begin{array}{l}\text { Assaf } \\
\text { Neto } \\
\text { (2014) }\end{array}$ \\
\hline & $\begin{array}{l}\text { Necessidade } \\
\text { de Capital de } \\
\text { Giro (NCG) }\end{array}$ & $N C G=\frac{(A C O-P C O)}{\text { Receita Líquida }}$ & $\begin{array}{l}\text { Mensurar a necessidade } \\
\text { de capital de giro em } \\
\text { relação à receita. }\end{array}$ & $\begin{array}{l}\text { Assaf } \\
\text { Neto } \\
(2014)\end{array}$ \\
\hline & $\begin{array}{l}\text { Prazo Médio de } \\
\text { Estocagem } \\
\text { (PME) }\end{array}$ & $P M E=\frac{\text { Estoque Médio }}{\begin{array}{c}\text { Custos dos Produtos Vendidos } \\
\times 360\end{array}}$ & $\begin{array}{l}\text { Indica o tempo médio } \\
\text { necessário para a } \\
\text { completa renovação dos } \\
\text { estoques da empresa. }\end{array}$ & $\begin{array}{l}\text { Assaf } \\
\text { Neto } \\
\text { (2014) }\end{array}$ \\
\hline & $\begin{array}{l}\text { Prazo Médio de } \\
\text { Pagamento } \\
\text { (PMP) }\end{array}$ & $P M P=\frac{\text { Fornecedor }}{\text { Compras }} \times 360$ & $\begin{array}{l}\text { É o período de tempo } \\
\text { médio, em dias, entre a } \\
\text { data de compra e o seu } \\
\text { efetivo pagamento }\end{array}$ & $\begin{array}{l}\text { Assaf } \\
\text { Neto } \\
(2014)\end{array}$ \\
\hline & $\begin{array}{l}\text { Prazo Médio de } \\
\text { Recebimento } \\
\text { (PMR) }\end{array}$ & $P M R=\frac{\text { Duplicatas a Receber }}{\text { Receita de Vendas }} \times 360$ & $\begin{array}{l}\text { É o período de tempo } \\
\text { médio, em dias, entre a } \\
\text { data da venda e o seu } \\
\text { efetivo recebimento }\end{array}$ & $\begin{array}{l}\text { Assaf } \\
\text { Neto } \\
(2014)\end{array}$ \\
\hline & $\begin{array}{c}\text { Equilíbrio } \\
\text { Financeiro de } \\
\text { Curto Prazo } \\
\text { (EFCP) }\end{array}$ & $E F C P=\frac{\text { Capital Circulante Líquido }}{\text { Receita Líquida }}$ & $\begin{array}{l}\text { Indica a folga financeira } \\
\text { de curto prazo da } \\
\text { empresa. }\end{array}$ & $\begin{array}{l}\text { Santos } \\
(2015)\end{array}$ \\
\hline
\end{tabular}

Figura 1: Fórmulas e Objetivos dos Indicadores Financeiros.

Fonte: Elaborado pelos autores (2018).

Notas: As contas/rubricas para os cálculos devem ser retiradas das demonstrações contábeis

Apesar dos trabalhos apresentados por Panucci-Filho e Cherobin (2011), Pimenta e Silva (2017) e Jones e Jacinto (2013), a implementação dessas soluções para cada empresa não é trivial ou de fácil realização. Construir essas informações para as PMEs, em especial para o setor de fertilizantes, apresenta uma experiência 
prática que permite servir de apoio, balizador ou mesmo comparação para outras realidades, conforme apresentado por Santos (2015).

\section{METODOLOGIA}

O presente estudo consiste em um estudo de caso. De acordo com Yin (2015, p. 32), "um estudo de caso é uma investigação empírica que investiga um fenômeno contemporâneo dentro de seu contexto da vida real, especialmente quando os limites entre fenômeno e contexto não estão claramente definidos".

A opção pelo estudo de caso, em particular a empresa escolhida, deu-se por sua característica organizacional ser encontrada com frequência nas PMEs. A empresa não consta de uma estrutura organizacional formal em conformidade com Antonik (2004), o qual afirma que frequentemente as PMEs não se organizam de maneira eficiente e adequada. Sua administração é realizada pelos proprietários, tendo um processo de tomada de decisão centralizado, segundo apresentado por Almeida e Wernke (2018) e Alves, Silva, Tavares e Dal-Soto (2013). Em adição, não possui avaliações financeiras e indicadores de desempenho que permitam uma gestão adequada dos recursos disponíveis, o que é típico das PMEs (Leoneti et al., 2016).

A sistematização do processo de organização financeira da empresa deu-se por 4 etapas, conforme apresentado na Figura 2.

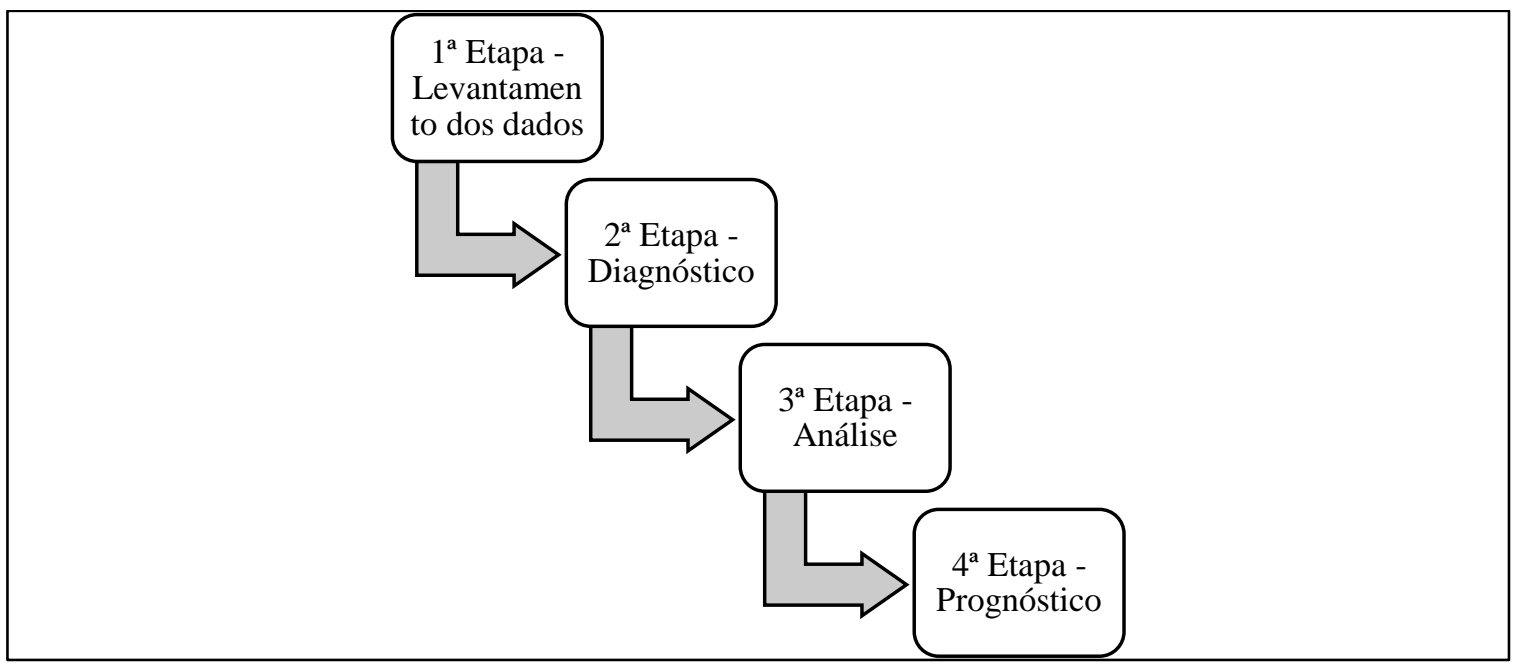

Figura 2: Etapas da sistematização do processo de organização financeira.

Fonte: Elaborado pelos autores (2018). 
A 1a Etapa consistiu em um levantamento de dados a fim de determinar em qual estágio de maturidade de gestão financeira a empresa encontra-se, sendo eles: preliminar, intermediário ou avançado, conforme apresentado por Rodrigues (2014). De acordo com Yin (2015), as fontes de evidência (dados) mais utilizadas em um estudo de caso são: documentação, registros em arquivos, entrevistas, observações diretas, observação participante e artefatos físicos.

O período para a coleta do material do presente estudo foi realizado entre os meses de janeiro a julho de 2017. A Tabela 1 a seguir apresenta o cargo, o tempo de empresa e o número de entrevistas realizadas com cada um dos entrevistados. As entrevistas não foram padronizadas, pois cada entrevistado foi indagado a respeito de seu setor específico.

Tabela 1: Resumo de entrevistados: cargo, tempo de empresa e número de entrevistas.

\begin{tabular}{c|c|c}
\hline Cargo Entrevistado & Tempo de empresa & $\begin{array}{c}\text { Número de } \\
\text { Entrevistas }\end{array}$ \\
\hline $\begin{array}{c}\text { Sócio/Presidente da Empresa/Diretor } \\
\text { Comercial e de Produção }\end{array}$ & 8 anos & 1 \\
\hline $\begin{array}{c}\text { Sócio/Presidente do conselho/Ex Diretor de } \\
\text { Operações e Financeiro }\end{array}$ & 2,5 anos & 6 \\
\hline Diretor Financeiro/Jurídico & $\begin{array}{c}1 \text { ano de jurídico, 4 meses } \\
\text { responsável pelo financeiro }\end{array}$ & 5 \\
\hline Gerente de Controladoria & 1 ano & 2 \\
\hline Supervisor de PCP & 6 anos & 4 \\
\hline
\end{tabular}

Fonte: Elaborado pelos autores (2018).

Para a realização das entrevistas utilizou-se um relatório semiestruturado, com perguntas abertas, aplicado individualmente, "in loco", de forma isolada, a fim de mapear e compreender a estrutura organizacional, dimensionar a capacidade produtiva e identificar os produtos e processos existentes.

Além das entrevistas realizadas, foram analisados documentos como orçamento, Demonstração do Resultado do Exercício (DRE), Balanço Patrimonial (BP), demonstrativos de fluxo de caixa, relatório de estoque, vendas, previsões mensais e planilhas de estimativas de custos. Foram presenciadas também reuniões do conselho e as de "performance", nas quais os setores comercial e financeiro da empresa foram analisados mensalmente. Todo o processo de levantamento de dados ocorreu entre janeiro e julho de 2017.

Por meio das entrevistas e análises documentais foi possível analisar a estrutura atual de gestão da empresa. Para melhor organização, as categorias de 
análise de conteúdo selecionadas para o presente estudo, em concordância com os tópicos apresentados no referencial teórico são demonstradas na Figura 3.

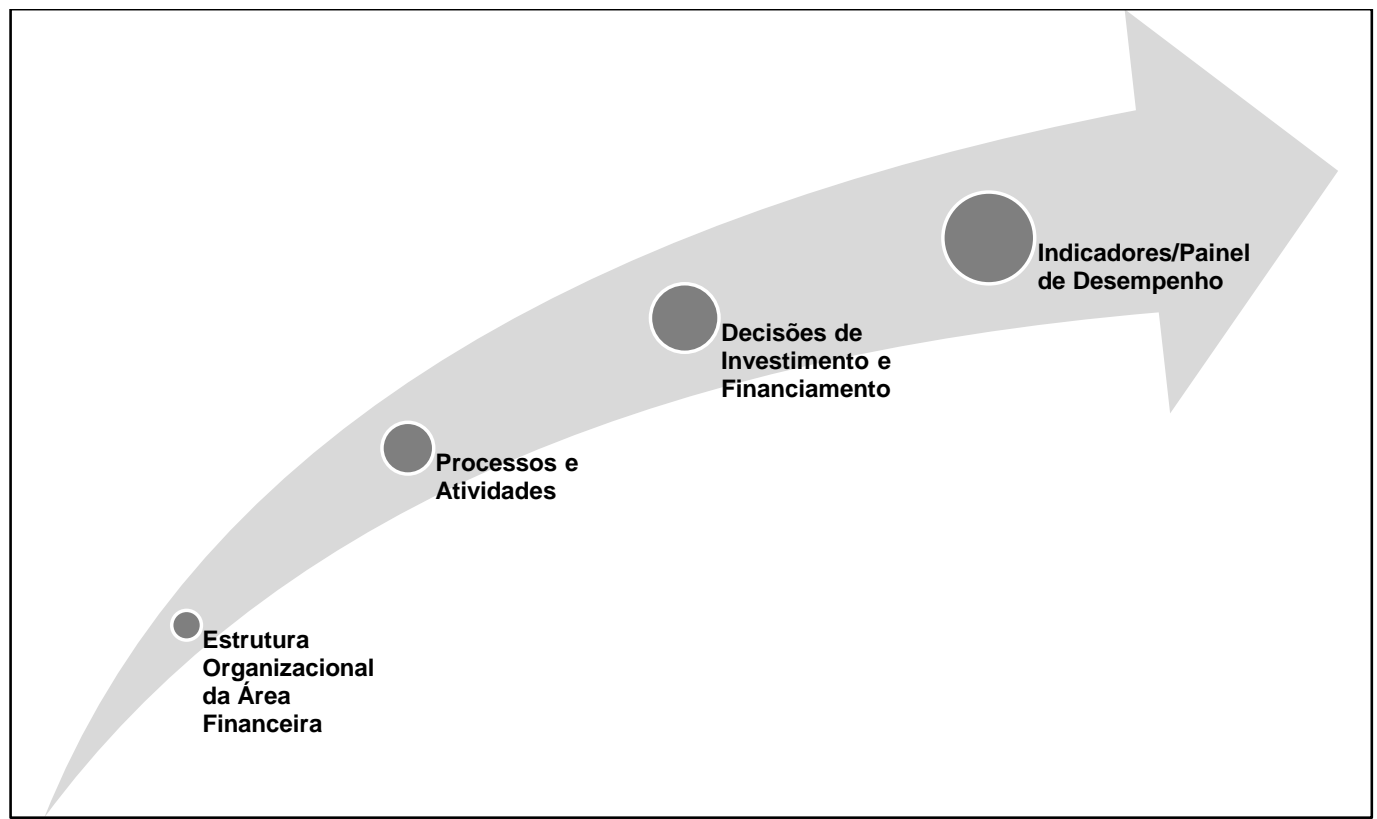

Figura 3: Categorias de análise.

Fonte: Elaborado pelos autores (2018).

A 2 $2^{\text {a }}$ Etapa consistiu na realização do diagnóstico da empresa, comparando os processos existentes aos trabalhos apresentados por Santos (2015), Lukason et al. (2015), Assaf Neto (2014) e Martins et al. (2015). Com isso, foi elaborado um quadro com as ações propostas (diagnóstico) para a adequação dos processos.

Um painel de desempenho comparando os indicadores da empresa à média do setor e o Benchmark permitiu a análise do desempenho financeiro da organização (3 $3^{\underline{a}}$ Etapa).

Por fim, um prognóstico foi apresentado (4⿳亠丷厂 Etapa) a fim de otimizar o processo de gestão financeira, contribuindo para a longevidade empresarial.

\section{RESULTADOS E DISCUSSÃO}

Nesta seção, será apresentada a empresa e as quatro etapas da sistematização do processo de organização financeira. 


\subsection{A Empresa}

A empresa investigada está sediada no interior do estado de São Paulo, mas possui uma filial no estado de Pernambuco. Foi constituída por um engenheiro agrônomo e agricultor local em outubro de 2008, contando com sede própria que abriga o escritório central e o centro de distribuição.

Em 2013, ampliou sua estrutura física passando a fabricar os seus próprios produtos. No mesmo ano, também inaugurou um laboratório para análises agronômicas.

Em 2014, a empresa contou com a entrada de um novo sócio que passou a ocupar o cargo de diretor de operações e financeiro. Atualmente, é o presidente do conselho, enquanto o sócio fundador acumula os cargos de presidente da empresa, diretor comercial e de produção.

Especializada em nutrição vegetal, contando com mais de 60 produtos em seu portfólio para aplicação via solo e foliar, incluindo uma linha certificada para a agricultura orgânica. A maioria dos produtos é de fabricação própria, a partir de matérias-primas importadas e nacionais. Há ainda uma pequena quantidade importada, pronta para distribuição.

No ano de 2016, a empresa apresentou uma carteira de 257 clientes, entre revendas, cooperativas e consumidores diretos, comercializando seus produtos em 17 estados brasileiros e no Distrito Federal.

Houve um rápido crescimento da empresa. O faturamento aumentou 12 vezes de 2009 , com faturamento de $R \$ 1,7$ milhão para $R \$ 20,4$ milhões (valores nominais) em 2015. Contudo, após esse crescimento, a empresa sofreu uma queda significativa de $32 \%$ entre 2015 e 2016, encerrando o ano com um faturamento de $\mathrm{R} \$ 13,7$ milhões.

A empresa possui uma estrutura organizacional a qual a área financeira, sob responsabilidade do diretor financeiro (CFO - Chief Financial Officer), contempla toda a área administrativa. Além de centralizar as funções típicas da área, tais como controladoria, finanças e tesouraria, também engloba os setores de $\mathrm{RH}$, jurídico e serviços gerais. 
$\mathrm{Na}$ controladoria, concentram-se, além da contabilidade e administração financeira, as áreas de tecnologia da informação (TI), comercial, almoxarifado, planejamento e controle da produção (PCP).

Sob a responsabilidade do tesoureiro, estão a captação de recursos e a importação. Apesar de apresentar uma estrutura organizacional com a controladoria separada da tesouraria, conforme enfatizam Gitman (1997) e Ross et al. (2002), na prática, isso não ocorre, uma vez que os proprietários centralizam o processo de tomada de decisão, conforme apresentado por Almeida e Wernke (2018), Alves, Silva, Tavares e Dal-Soto (2013).

\subsection{Levantamento de Dados}

Informações subjetivas foram obtidas através das entrevistas realizadas e de observações do cotidiano da empresa. Estas informações obtidas na entrevista são de fundamental importância para a avaliação do grau de maturidade dos processos de gestão existentes na empresa.

É um consenso, entre os entrevistados, que o organograma da empresa é alterado com frequência, com mudanças em cargos, funções e também pessoas, sem uma estruturação eficiente, conforme apresentado por Antonik (2004).

Os relatórios analisados mostram altos valores investidos em estoques (23\% dos ativos circulantes) e recebíveis ( $47 \%$ dos ativos circulantes) em função das vendas a prazo e por períodos de sazonalidade, influenciando o caixa e obrigando a empresa a recorrer ao cheque especial, confirmando o que foi apresentado por Martínez-Sola et al. (2014).

O proprietário afirma, em respostas às entrevistas, que a maior dificuldade enfrentada nos últimos meses pela empresa é a redução de receitas. Fato este que também pôde ser observado através da avaliação dos relatórios da empresa.

Uma das maiores dificuldades enfrentadas pela empresa, exposta em reuniões e entrevistas, é relacionada à informação: a falta ou qualidade dela. $\mathrm{O}$ proprietário afirma que este problema:

[...] afeta drasticamente a gestão do capital de giro da empresa, na medida que sem a informação correta de caixa, estoques, contas a pagar e receber dificultam muito um planejamento adequado e uma correta administração do capital de giro. 
As entrevistas revelaram dificuldades na gestão do capital de giro, um fator de grande representatividade na taxa de mortalidade das PMEs, conforme apresentado por Santini et al. (2015). Esta constatação reforça o trabalho empírico apresentado por Panucci-Filho e Cherobin (2011). Observa-se que a administração do capital de giro é realizada intuitivamente, o que, segundo Orobia, Byabashaija, Munene, Sejjaaka e Musinguzi (2013), é natural para empresas de pequeno porte, ainda que não desejável.

A sazonalidade das vendas é a responsável pelos maiores desafios encontrados na gestão do capital de giro (Zouain et al., 2011). Os recebimentos da empresa estão concentrados em dois momentos do ano, sendo o primeiro em maio e o segundo em setembro. Como constatado no trabalho apresentado por Pimenta e Silva (2017), para amenizar os efeitos provocados pela sazonalidade, utiliza-se de adiantamento dos recebíveis e linhas de crédito com duplicatas em garantia, aumentado os níveis de estoques e de duplicatas a receber, conforme descrito por Zouain et al. (2011).

É importante ressaltar que, com a redução do fluxo de receita, há uma extensão do ciclo financeiro, pois o prazo médio de estocagem e o prazo médio de recebimento (PMR) serão mais longos. Com efeito, estenderão a necessidade de capital de giro, que deve ser financiada com fontes de longo prazo, obrigando a empresa a recorrer ao crédito rotativo de curto prazo (Assaf Neto, \& Tibúrcio Silva, 2012).

Alves et al. (2013) argumentaram que um dos maiores desafios enfrentados pelas pequenas empresas é prever as mudanças no mercado e antecipar-se a elas. Assim, a maior dificuldade enfrentada ao fazer o orçamento de caixa foi a elaboração do plano de vendas em relação ao seu volume e condições de pagamento, em consonância com o trabalho empírico apresentado por Panucci-Filho e Cherobin (2011).

Também foi possível constatar que o planejamento do estoque é realizado de acordo com a previsão trimestral de vendas, fornecida pelo departamento comercial. Apurou-se um elevado valor investido no estoque em função das vendas não concretizadas. Com isso, surge a necessidade de aprimorar a previsão de vendas 
para conseguir otimizar o planejamento dos estoques e de produção, conforme apontado por Ivanovich e Viktorovna (2016).

A gestão do estoque é baseada na intuição, como apresentado por Pillai (2014), inexistindo ferramentas que otimizam o custo de estocagem, conforme proposto por Mokhtari (2018). Segundo os entrevistados, há elevado nível de estoque em função de itens com compra mínima de matéria-prima importada que, devido aos custos e tempo de reposição, exige pedidos maiores.

Outra importante constatação é a inexistência do cálculo da taxa de retorno exigida pelos proprietários de capital, o que, segundo Assaf Neto (2014), é fundamental para a administração financeira de uma empresa, impossibilitando cálculos essenciais, tais como VPL e TIR.

Fica evidente a falta de planejamento para as decisões de investimentos, uma vez que inexistem ferramentas para avaliar os resultados dos investimentos realizados. Assim, como apresentado por Moreira et al. (2013), constatou-se que os demonstrativos contábeis são tratados como mera obrigação fiscal e, com isto, também foi possível observar a ausência de indicadores financeiros, reforçando o que foi apresentado por Leoneti, Nirazawa e Oliveira (2016), Vogel e Wood Jr. (2013), com relação às dificuldades das PMEs em utilizarem indicadores de desempenho tradicionais.

De forma análoga ao trabalho empírico apresentado por Jones e Jacinto (2013), o levantamento dos dados apresentados contribui para diagnosticar o estado financeiro da empresa estudada, permitindo diagnosticá-la, a fim de mantê-la sólida no mercado.

\subsection{Diagnóstico}

A partir dos resultados encontrados por meio da avaliação qualitativa, a Figura 4 sintetiza as principais oportunidades de melhorias com suas respectivas propostas de ações.

\begin{tabular}{|c|ll|}
\hline \multicolumn{1}{|c|}{$\begin{array}{c}\text { Oportunidades de } \\
\text { Melhoria }\end{array}$} & \multicolumn{1}{c|}{ Propostas de Ações } \\
\hline \multirow{3}{*}{ Estrutura Organizacional } & $\begin{array}{l}\text { 1. Separação do financeiro das demais áreas do administrativo } \\
\text { 2. } \begin{array}{l}\text { Segmentar a controladoria da tesouraria na prática, como está no } \\
\text { organograma }\end{array} \\
\text { 3. Firmar um organograma definitivo, baseado em funções a serem } \\
\text { desempenhadas }\end{array}$ \\
\hline
\end{tabular}




\begin{tabular}{|c|c|}
\hline $\begin{array}{l}\text { Administração do Capital } \\
\text { de Giro, Planejamento e } \\
\text { Controle }\end{array}$ & $\begin{array}{l}\text { 1. Adequação das informações, quanto a sua qualidade e tempo } \\
\text { 2. Utilização de indicadores financeiros }\end{array}$ \\
\hline Orçamento de Caixa & $\begin{array}{l}\text { 1. Separar o caixa gerado pela variação dos investimentos e } \\
\text { financiamentos } \\
\text { 2. Melhorar a qualidade das previsões de receitas e custos }\end{array}$ \\
\hline $\begin{array}{l}\text { Gestão do Contas a } \\
\text { Receber }\end{array}$ & $\begin{array}{l}\text { 1. Buscar maior diversificação de regiões, culturas e clientes } \\
\text { 2. Melhor distribuição de prazos e receitas } \\
\text { 3. } \\
\text { Buscar novas alternativas de crédito junto aos clientes }\end{array}$ \\
\hline Gestão do Estoque & $\begin{array}{l}\text { 1. Necessidade de melhor planejamento de estoques } \\
\text { 2. Melhorar a previsão das vendas } \\
\text { 3. Avaliar a utilização de ferramentas de gestão de estoque como o } \\
\text { sistema ABC }\end{array}$ \\
\hline $\begin{array}{l}\text { Decisões de } \\
\text { Financiamento e } \\
\text { Investimento }\end{array}$ & $\begin{array}{l}\text { 1. Definir a taxa de retorno exigida pelos proprietários de capital } \\
\text { 2. Implementar na empresa os modelos para avaliação e seleção de } \\
\text { alternativas de investimento } \\
\text { 3. Realizar os cálculos dos custos de capital próprio, de terceiros e } \\
\text { total e grau de alavancagem financeira }\end{array}$ \\
\hline
\end{tabular}

Figura 4: Resumo de Oportunidades de Melhoria e Propostas de Ações.

Fonte: Elaborado pelos autores (2018).

Iniciou-se o diagnóstico (2ª Etapa) a partir da estrutura organizacional da área financeira. Considerando as particularidades (e limitações) existentes na organização e direcionando para propostas de ações necessárias, respaldadas na revisão de literatura, é apresentado um novo modelo de organograma na Figura 5.

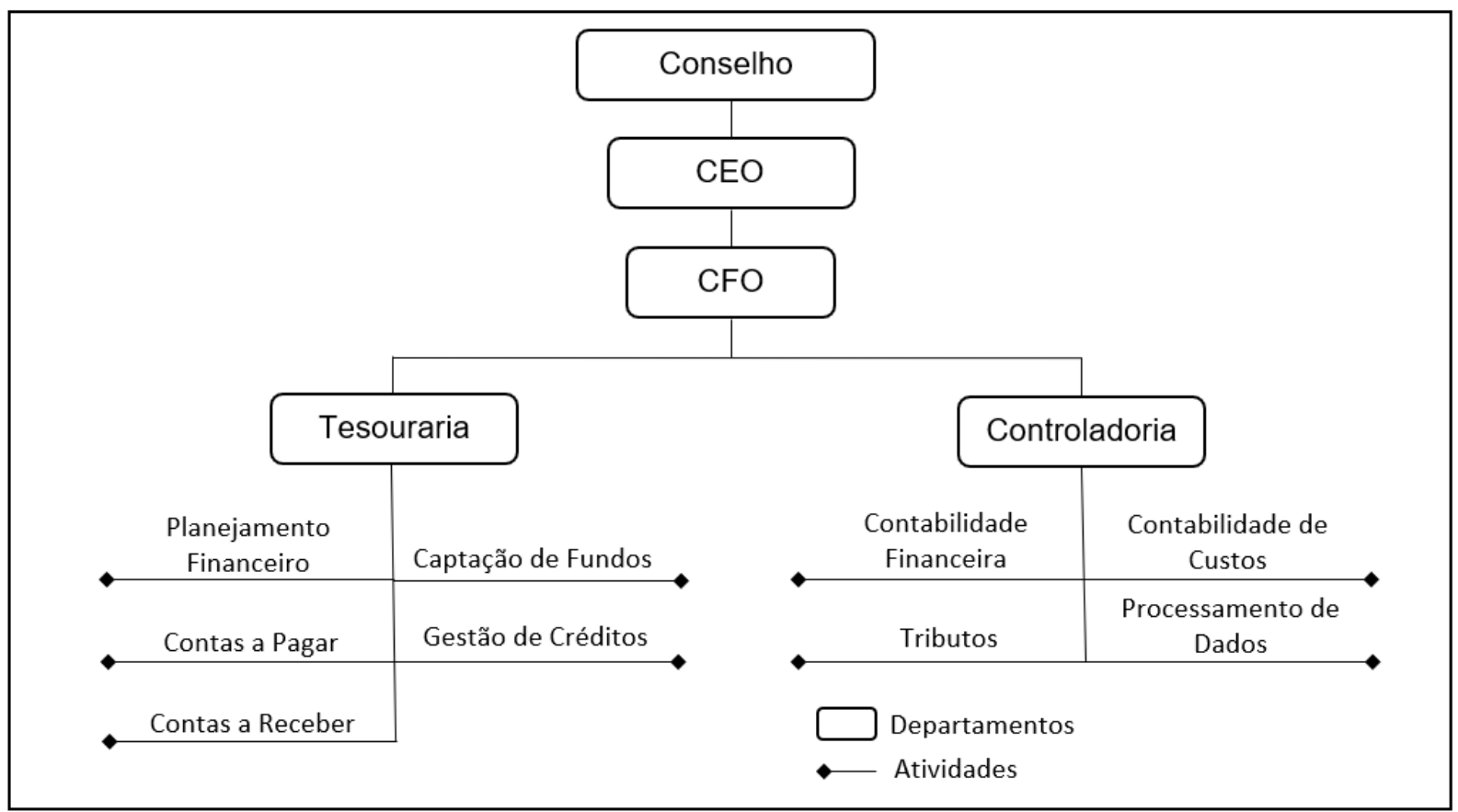

Figura 5: Proposta de Modelo de Organograma da Área Financeira Fonte: Elaborado pelos autores (2018). 
A área financeira da empresa fica formalmente dividida entre a tesouraria e a controladoria. Na tesouraria estão concentradas as atividades de planejamento financeiro, captação de fundos, gestão do caixa e de crédito. A controladoria contempla a parte tributária, contabilidade (custos e financeira) e o processamento de dados.

A divisão de tarefas segue o modelo proposto por Mintzberg (2003). Foi dividida entre as principais funções organizacionais, fornecendo base para a ação gerencial (Marin-Idarraga, \& Cuartas-Marin, 2013) a partir da segregação das atividades e de acordo com suas características e necessidade de recursos (Daft, 2003).

Apesar da existência de uma estrutura departamentalizada que contempla a criação de métricas de desempenho por áreas, alguns departamentos são tratados como atividades. Com isso, mantém-se uma estrutura enxuta, conforme demonstrado por Gonzalez-Loureiro et al. (2017), e um processo mais curto de tomada de decisões, de acordo com Reis et al. (2018). Essa assertiva torna-se essencial para as PMEs em que os recursos são limitados.

Com a departamentalização e a segregação das atividades é possível analisar os gastos por departamento, permitindo maior gestão e, assim, o orçamento de custo e de despesas tornam-se mais assertivos.

Apesar dos desafios impostos pela sazonalidade na gestão do capital de giro, conforme apresentado por Zouain et al. (2011), seus efeitos são amenizados por um orçamento de caixa que considera o orçamento de vendas em função do ciclo da safra (concentrados em dois momentos do ano - maio e setembro) e também do orçamento de custo que, adequados a esta particularidade, permitirá um melhor monitoramento do negócio, conforme apresentado por Maduekwe e Kamala (2016).

Por meio da diversificação de novos clientes e novos mercados, busca-se uma melhor gestão dos recebíveis com a distribuição dos prazos de vendas e períodos de receita, minimizando os efeitos apresentados por Zouain et al. (2011), em que a empresa é obrigada a realizar o adiantamento dos recebíveis e linhas de crédito com duplicatas como garantia, aumentado os níveis de duplicatas a receber e de estoques.

Os demonstrativos apresentam valores significativos alocados em estoque, assim, a gestão do estoque é vinculada ao orçamento de vendas, com ajustes 
mensais, em função das vendas concretizadas, alinhando o nível de estoque com a necessidade do mercado.

Para garantir a acuracidade do estoque, ele foi classificado segundo o critério ABC, conforme apresentado por lqbal et al. (2017). A utilização do sistema ABC aprimora o controle de estoque da empresa, priorizando os itens mais valiosos e os procedimentos necessários para o seu controle (Gitman, 1997). Entende-se que a maior acuracidade do estoque, um controle mais preciso dos prazos de ressuprimento e um acompanhamento mensal do orçamento de vendas são suficientes para equalizar os níveis de estoque.

Conforme apresentado por Nascimento (2013), o cálculo da taxa de retorno exigida pelos proprietários de capital é fundamental tanto para as decisões de investimento quanto para as de financiamento.

Para o cálculo do $\mathrm{K}_{\mathrm{e}}$, utilizou-se o modelo CAPM, como apresentado por Assaf Neto (2014). Para a taxa de retorno de ativos livres de risco $\left(\mathrm{R}_{\mathrm{F}}\right)$, foi considerado $11,13 \%$ referente ao CDI do dia 23 de maio de 2017 . O prêmio de mercado foi considerado um valor de $6 \%$, média do setor.

O coeficiente beta $(\beta)$ foi determinado através de análises de empresas do setor de fertilizantes e da indústria química. Para o valor do $\beta$ (desalavancado), foi utilizado 0,47 referente à média do setor. Esse valor foi obtido no dia 23 de maio de 2017, referente aos últimos três anos com variações diárias.

Obteve-se o valor de 13,95\% para o Custo do Capital Próprio para a empresa. Em sequência, foi possível calcular o Custo Total de Capital através da fórmula do CMPC, apresentada por Assaf Neto (2014), obtendo-se o valor de 19,24\%.

A Tabela 2 apresenta os indicadores financeiros calculados para a empresa. A escolha dos indicadores para o Painel de Desempenho deu-se a partir do modelo proposto por Santos (2015), Lukason et al. (2015), Assaf Neto (2014) e Martins et al. (2015), contando com indicadores de rentabilidade, lucratividade, geração de caixa, endividamento e liquidez.

Tabela 2: Painel de Desempenho

\begin{tabular}{ccccccc}
\hline Categorias & Indicadores & Periodicidade $^{2}$ & Meta $^{\mathrm{a}}$ & 2016 & Setor $^{\mathrm{b}}$ & Benchmark $^{\mathrm{C}}$ \\
\hline Rentabilidade & Retorno Residual & Anual & $\# \#$ & $-33,7 \%$ & $-53,0 \%$ & $2,0 \%$
\end{tabular}




\begin{tabular}{|c|c|c|c|c|c|c|}
\hline & ROI & Mensal & \#\# & $-14,5 \%$ & $-3,4 \%$ & $13,6 \%$ \\
\hline & ROE & Mensal & \#\# & $-31,1 \%$ & $-45,9 \%$ & $26 \%$ \\
\hline Lucratividade & Margem Bruta & Mensal & \#\# & $66,4 \%$ & $18,2 \%$ & $43,6 \%$ \\
\hline & Margem Operacional & Mensal & \#\# & $-0,04 \%$ & $5,1 \%$ & $63,9 \%$ \\
\hline & Margem Líquida & Mensal & \#\# & $-22,5 \%$ & $-6,9 \%$ & $31,6 \%$ \\
\hline $\begin{array}{l}\text { Geração de } \\
\text { Caixa }\end{array}$ & Margem EBTIDA & Mensal & \#\# & $-0,04 \%$ & $10,1 \%$ & $76,2 \%$ \\
\hline & Giro do Ativo & Mensal & \#\# & $54,0 \%$ & $138,3 \%$ & $320,0 \%$ \\
\hline & Crescimento de Receita & Anual & \#\# & $-32,7 \%$ & $4,0 \%$ & $14,8 \%$ \\
\hline & $\begin{array}{l}\text { Capacidade de Cobertura } \\
\text { de Juros }\end{array}$ & Mensal & \#\# & $-0,002$ & 0,5 & 4,3 \\
\hline Endividamento & Endividamento Geral & Mensal & \#\# & $55,2 \%$ & $29,3 \%$ & $7,9 \%$ \\
\hline & $\begin{array}{l}\text { Endividamento de Curto } \\
\text { Prazo }\end{array}$ & Mensal & \#\# & $57,4 \%$ & $59,0 \%$ & $21,7 \%$ \\
\hline & $\begin{array}{l}\text { Grau de Alavancagem } \\
\text { Financeira }\end{array}$ & Mensal & \#\# & 2,1 & 0,8 & n.d. ${ }^{d}$ \\
\hline Liquidez & Liquidez Corrente & Mensal & \#\# & 1,8 & 1,7 & 3,4 \\
\hline & $\begin{array}{l}\text { Necessidade de Capital de } \\
\text { Giro }\end{array}$ & Mensal & \#\# & 1,2 & 0,1 & $-0,3$ \\
\hline & $\begin{array}{l}\text { Equilíbrio Financeiro de } \\
\text { Curto Prazo }\end{array}$ & Mensal & \#\# & 0,6 & 0,1 & 0,62 \\
\hline & $\begin{array}{l}\text { Coeficiente de Efeito } \\
\text { Tesoura }\end{array}$ & Mensal & \#\# & $-0,6$ & $-0,04$ & 0,1 \\
\hline & $\begin{array}{l}\text { Prazo Médio de } \\
\text { Estocagem }\end{array}$ & Mensal & \#\# & 373,1 & 91,9 & 14,1 \\
\hline
\end{tabular}

Fonte: Elaborado pelos autores (2018).

Notas: aA definir; ${ }^{b}$ Média de seis empresas do setor da Indústria Química registradas na Bovespa, sendo duas dessas da Indústrias de Fertilizantes, que são as empresas Fertilizantes Heringer S.A e Nutriplant Indústria e Comércio S.A; cMelhor valor observado entre todas as empresas do setor da Indústria Química. ${ }^{d}$ Não há dados disponível.

\subsection{Análise}

Com base nos resultados apresentados na Tabela 2, foi possível realizar uma análise da situação financeira da empresa ( $3^{\text {a }}$ Etapa), comparando-a com as demais empresas do setor e com o Benchmark. Utilizou-se de resultados médios do setor e benchmark como forma de avaliar a empresa perante os pares do mercado em atenção ao que foi apresentado por Maté-Sánchez-Val et al. (2017), em que as PMEs com indicadores financeiros longe de seus benchmarks incorrem em custos por estarem em desequilíbrio.

A partir da Margem Bruta, observou-se que a empresa possui custos proporcionalmente menores em relação às demais, o que entrega a ela um melhor resultado. Em contrapartida, sua Margem Operacional está abaixo do setor, 
sugerindo que o resultado esteja sendo comprometido por maior nível de despesas operacionais (administrativas e comerciais). Esse resultado é agravado pelas despesas financeiras, reduzindo a Margem Líquida a níveis abaixo do setor.

Com uma Margem Operacional negativa, seu reflexo se estenderá para o Retorno Residual, Retorno Sobre o Patrimônio e Retorno Sobre o Investimento. Com esse resultado, não há recursos para o pagamento das despesas financeiras, implicando em uma incapacidade de cobertura de juros, obrigando que as despesas financeiras sejam pagas a partir de novas dívidas, aumentando o endividamento, conforme observado nos indicadores de endividamentos geral e de curto prazo.

O Endividamento de Curto Prazo representa mais da metade da dívida total, comprometendo a gestão do caixa e a liquidez da empresa que, de acordo com Matias (2007), a empresa apresenta o efeito tesoura. Como consequência, utiliza-se de créditos onerosos de curto prazo para financiar sua Necessidade de Investimento em Capital de Giro (NIG), tornando seus negócios dependentes da manutenção desses passivos (Assaf Neto, \& Tibúrcio Silva, 2012).

De acordo com Matias (2007, p. 41), overtrading (efeito tesoura) "significa o ato de fazer negócios superiores à capacidade de financiamento da Necessidade de Capital de Giro decorrente desses negócios".

A empresa possui um índice de LC desejável (>1), segundo Assaf Neto e Tibúrcio Silva (2012). Contudo, esse efeito é decorrente de um elevado capital de giro em função de contas a receber e é potencializado pelo baixo giro do estoque frente ao padrão médio do setor e do benchmark. Como o giro dos estoques é baixo, o giro do ativo também é baixo, o que implica uma menor geração de receita frente a seu potencial.

Na mesma direção, o Equilíbrio Financeiro de Curto Prazo aparenta estar em um nível ótimo em relação ao benchmark. Entretanto, esse valor também é proveniente do elevado capital de giro da empresa investido em circulante, porém, com baixo giro, novamente evidenciado pelo Prazo Médio de Estocagem.

Forte, Barros e Nakamura (2013) encontraram fortes evidências acerca da alavancagem financeira em pequenas e médias empresas brasileiras, demonstrando que existe uma relação inversa entre a lucratividade e o grau de alavancagem de uma PME. 
O Valor apresentado do GAF foi de 2,1 e representaria um retorno excepcional para os acionistas, o que não ocorre na prática, uma vez que tanto o ROE como o ROI são negativos. Portanto, o custo da dívida é mais alto que seu retorno. Assaf Neto (2014) demonstra o cálculo do GAF pela divisão do retorno sobre patrimônio líquido (ROE) pelo retorno sobre o investimento (ROI), ou seja, $\mathrm{GAF}=\mathrm{ROE} / \mathrm{ROI}$.

\subsection{Prognóstico}

A partir da análise do painel de desempenho, recomenda-se reavaliar o dimensionamento do estoque da empresa. O elevado nível de estoque associado a um baixo giro contribui para a descapitalização da empresa. Essa reavaliação ocorre por meio de uma maior acuracidade do estoque e do controle preciso dos prazos de ressuprimento vinculados diretamente ao orçamento de vendas.

O dimensionamento inapropriado dos estoques, além de influenciar o Prazo Médio de Estocagem que, aliado a um Prazo Médio de Recebimento também elevado, implica em um ciclo operacional muito extenso. Consequentemente, a NCG (Necessidade de Capital de Giro) expande e a empresa tende a ser financiada com recursos de curto prazo (Martins et al., 2015).

Na mesma direção, existe a necessidade de reavaliar o dimensionamento dos gastos administrativos e comerciais de modo a ajustá-los ao padrão do setor ou benchmark. É fundamental que a empresa diminua seus gastos operacionais para que consiga obter melhor resultado.

O Capital de Giro também precisa ser reavaliado, sendo necessária a substituição das dívidas de curto prazo para dívidas de longo prazo através da renegociação com os credores. Volta-se também a atenção para o redimensionamento do saldo de tesouraria (ST), pois, sendo positiva a necessidade de capital de giro da empresa, seu ST também deveria ser positivo, conforme apresentado por Assaf Neto e Tibúrcio Silva (2012).

Destaca-se também a importância da identificação de ativos (investimentos) subutilizados na empresa que possuam capacidade de gerarem receitas ou serem vendidos, permitindo, com isto, uma geração excedente de receitas.

A Figura 4 apresenta todas as etapas, consolidando as 4 fases apresentadas anteriormente. 


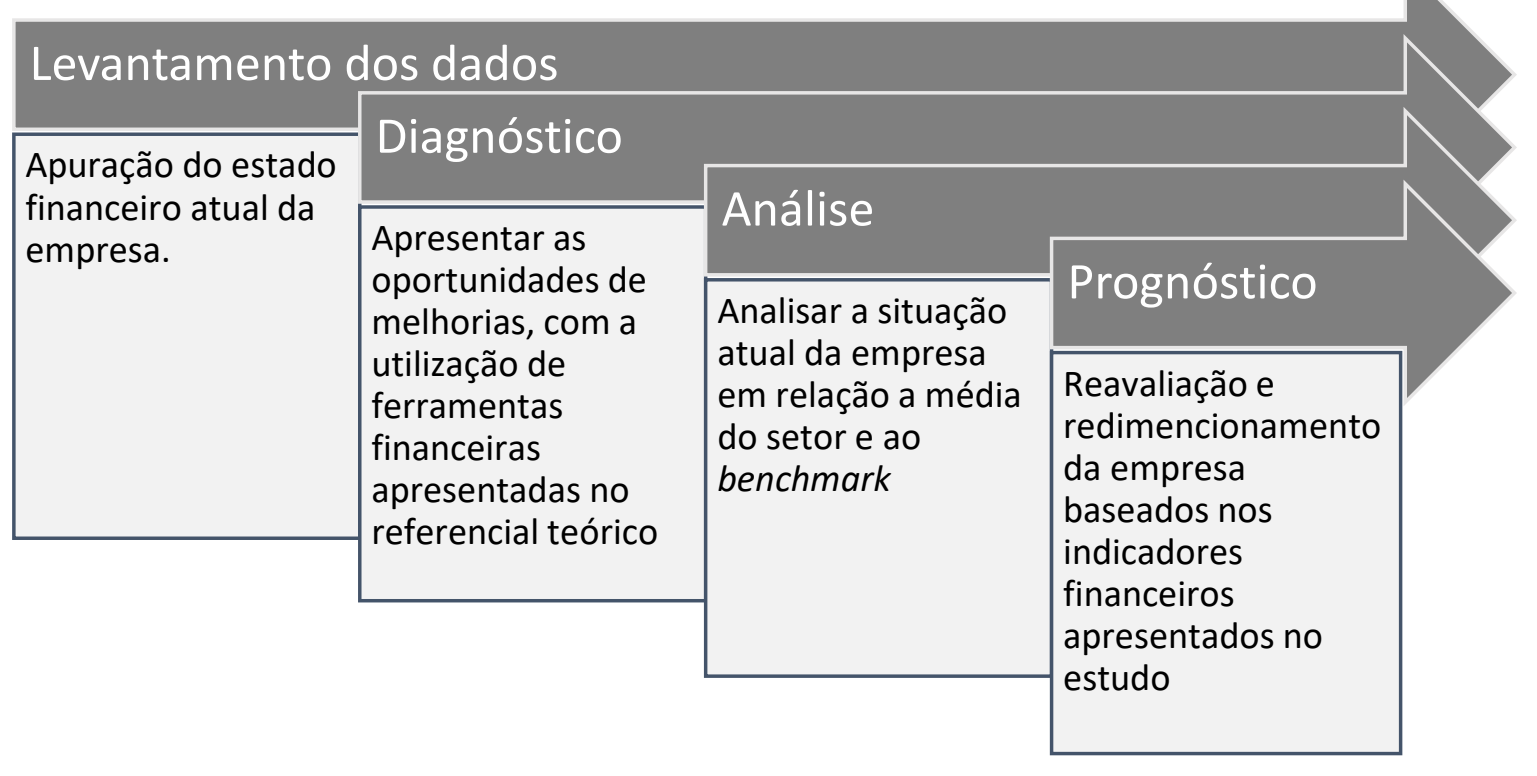

Figura 6: Consolidação das 4 fases apresentadas

Fonte: Elaborado pelos autores (2018).

A Figura 6 sintetiza as etapas de "como" uma empresa de pequeno porte pode construir o seu modelo de gestão financeira partindo do levantamento dos dados, diagnóstico da situação atual, análise das informações e prognóstico.

\section{CONSIDERAÇÕES FINAIS}

A motivação para a realização deste trabalho foi elaborar um modelo de gestão financeira aplicada em uma empresa de pequeno/médio porte situada no interior do estado de São Paulo, de modo a compreender como organizar e gerenciar a área financeira da empresa, sintetizando um processo dividido em 4 etapas (levantamento de informações, diagnóstico, análise e prognóstico).

Baseado na coleta interna de informações e respaldado pelo referencial teórico (1ª Etapa), realizou-se o diagnóstico da situação atual da administração financeira da referida empresa (2 $2^{\mathrm{a}}$ Etapa).

Apurou-se uma carência de profissionalização na área de gestão, sendo uma característica de grande parte das empresas brasileiras de mesmo porte. Nesse sentido, montou-se um organograma com departamentos e atividades que se enquadram nas características e necessidades das PMEs. 
Foi apresentado como elaborar um "Painel de Desempenho". O intuito foi mostrar a real situação financeira da empresa (3ª Etapa), ratificando as informações obtidas a partir das entrevistas e demais fontes.

Esses indicadores mostram que a empresa possui um grande gargalo em suas despesas administrativas, comerciais e financeiras, que acabam consumindo todo o seu resultado. O que acarreta uma situação de elevado endividamento, baixa liquidez e efeito tesoura.

Com base nestas informações, o gestor pode adotar medidas que possibilitem remediar os processos que não apresentam os resultados desejados, ajustando os indicadores de rentabilidade, lucratividade, geração de caixa, endividamento ou liquidez, uma vez que, conhecendo cada componente do indicador, pode geri-los a fim de aproximá-los do benchmark, agindo de maneira proativa diante das estratégias de gestão (4를 Etapa).

Em adição, o trabalho demonstrou a importância da utilização de uma estrutura de indicadores, um sistema de gestão operando corretamente com informações de qualidade, permitindo avaliar minuciosamente todas as alternativas de investimento.

A literatura consultada apresentou diversos indicadores além dos expostos neste trabalho. Contudo, para o caso específico aqui tratado, levando-se em consideração o porte da empresa e as limitações impostas ao segmento de fertilizantes, que é caracterizado por forte concorrência de grandes empresas e influência de variáveis macroeconômicas, entende-se que os indicadores aqui propostos são suficientes para permitir um melhor acompanhamento e análise da realidade financeira e econômica da empresa.

Dessa forma, o trabalho apresentou, na prática, como organizar e gerenciar a área financeira de uma empresa de pequeno porte elaborando indicadores de modo a permitir uma gestão eficiente dos recursos financeiros, aumentando suas chances de se perpetuar no mercado.

A presente pesquisa concentrou suas atenções em apenas uma empresa de pequeno e médio porte no segmento de fertilizantes. Como forma de continuidade deste trabalho, sugere-se que novos estudos sejam realizados em PMEs, comparando empresas de mesmo setor e também de diferentes setores para que 
seja possível obter e comparar informações e, assim, buscar soluções que sejam mais adequadas a essas empresas.

Cabe ressaltar que estas contribuições e conclusões, sejam contribuindo para a literatura das PMEs com técnicas que melhorem a competividade das empresas do setor, ou mesmo as contribuições indiretas, como a criação de empregos e renda para as famílias ligadas ao setor estudado, foram propostas especificamente para a empresa em questão e, portanto, podem não ser ideais em outros casos.

$\mathrm{Na}$ mesma direção, ressalta-se a questão temporal do trabalho, quando os resultados são baseados e válidos apenas para o período em que as informações foram coletadas, sendo então, uma limitação do presente estudo.

\section{REFERÊNCIAS}

Abisolo (2016). Associação Brasileira das Indústrias de Tecnologia em Nutrição Vegetal. Anuário Brasileiro de Tecnologia em Nutrição Vegetal. São Paulo.

Almeida, I. X. de, \& Wernke, R. (2018). Estilos Gerenciais dos Dirigentes de Pequenas Empresas: Estudo Baseado no Ciclo de Vida Organizacional. Evista de Empreendedorismo e Gestão de Pequenas Empresas, v. 7(3), pp. 110-140.

Almeida, P. O. de. (2018). O neoliberalismo e a crise dos Critical Legal Studies. Rev. Direito Práx, v. 9(4), pp. 2229-2250.

Alves, J. N., Silva, T. B. da, Tavares, C. E. M., \& Dal-Soto, F. (2013). A utilização do planejamento estratégico como ferramenta de gestão na pequena empresa. Revista Da Micro $E$ Pequena Empresa, v. 7(2), pp. 80-100.

Antonik, L. R. (2004). A administração financeira das pequenas e médias empresas. Revista FAE Business, v. 8, pp. 35-38.

Assaf Neto, A. (2014). Finanças corporativas e valor. 7. ed. São Paulo: Atlas.

Assaf Neto, A., \& Tibúrcio Silva, C. A. (2012). Administração do Capital de Giro. 4 ed. São Paulo: Atlas.

Atnafu, D., \& Balda, A. (2018). The impact of inventory management practice on firms' competitiveness and organizational performance: Empirical evidence from micro and small enterprises in Ethiopia. Cogent Business \& Management, v. 5(1), pp. 1-16.

Barbalho Júnior, C. G. P., \& Callado, A. A. C. (2008). Análise da competitividade do setor de fertilizantes da Região Nordeste. Revista Brasileira de Estratégia, v. 1(3), pp. 307-318.

Barros, G. S. C., \& Silva, S. F. (2008). A balança comercial do agronegócio brasileiro de 1989 a 2005. Revista de Economia e Sociologia Rural, v. 46(4), pp. 905-935. 
Carvalho, C J. (2015). Como a gestão de práticas de oferta de crédito impacta a de estoque. RAC-Revista de Administração Contemporânea, v. 19(spe), pp. 77-97.

Chittenden, F., \& Derregia, M. (2015). Uncertainty, irreversibility and the use of "rules of thumb" in capital budgeting. The British Accounting Review, v. 47(3), pp. 225-236.

Conceição, O. C., Saraiva, M. V., Fochezatto, A., \& Aniceto França, M. T. (2018). Brazil's Simplified Tax Regime and the longevity of Brazilian manufacturing companies: A survival analysis based on RAIS microdata. Economia, v. 19(2), pp. 164-186.

Copiello, S. (2016). A Discounted Cash Flow variant to detect the optimal amount of additional burdens in Public-Private Partnership transactions. MethodsX, v. 3(Supplement C), pp. 195-204.

Daft, R. L. (2003). Organizações: teoria e projetos. São Paulo: Pioneira Thomsom Learning.

Dias, V. P., \& Fernandes, E. (2006). Fertilizantes: uma visão global sintética. BNDES Setorial, v. 24(97), p. 138.

Erdogan, A. I. (2018). Factors affecting SME access to bank financing: an interview study with Turkish bankers. Small Enterprise Research, v. 25(1), pp. 23-35.

Escrivão Filho, E., Albuquerque, A. F., Nagano, M. S., Philippsen Junior, L. A., \& Oliveira, J. de. (2017). Identifying SME mortality factors in the life cycle stages: an empirical approach of relevant factors for small business owner-managers in Brazil. Journal of Global Entrepreneurship Research, v. 7(1), p. 5.

Formenti, M. C. L., \& Martins, I. C. S. (2015). Análise da gestão financeira nas micro e pequenas empresas de Osasco. REMIPE-Revista de Micro e Pequenas Empresas e Empreendedorismo ea Fatec Osasco, v. 1(1), pp. 40-61.

Forte, D., Barros, L. A., \& Nakamura, W. T. (2013). Determinants of the capital structure of small and medium sized Brazilian enterprises. BAR-Brazilian Administration Review, v. 10(3), pp. 347-369.

Gitman, L. J. (1997). Princípios de administração financeira. 7ed. São Paulo: Harbra.

Gonzalez-Loureiro, M., Sousa, M. J., \& Pinto, H. (2017). Culture and innovation in SMEs: the intellectual structure of research for further inquiry. European Planning Studies, v. 25(11), pp. 1908-1931.

Hall, R. J., Costa, V. C. da, Kreuzberg, F., Moura, G. D., \& Hein, N. (2012). Contabilidade como uma ferramenta da gestão: um estudo em micro e pequenas empresas do ramo de comércio de Dourados-MS. Revista Da Micro e Pequena Empresa, v. 6(6), pp. 4-17.

Iqbal, Q., Malzahn, D., \& Whitman, L. (2017). Statistical analysis of multi-criteria inventory classification models in the presence of forecast upsides. Production \& Manufacturing Research, v. 5(1), pp. 15-39.

Ivanovich, P. P., \& Viktorovna, I. B. (2016). Issues of Forming Inventory Management System in Small Businesses. International Review of Management and Marketing, v. 6(3), pp. 522-527.

Jones, G. D. C., \& Jacinto, A. C. de O. (2013). Análise da Gestão dos Investimentos em Capital de Giro Por Meio do Modelo Fleuriet em uma Empresa do Agronegócio: Um Estudo De Caso. Revista Em Agronegócios e Meio Ambiente, v. 6(1), pp. 9-30. 
Leoneti, A., Nirazawa, A., \& Oliveira, S. (2016). Proposta de índice de sustentabilidade como instrumento de autoavaliação para micro e pequenas empresas (MPEs). REGE-Revista de Gestão, v. 23(4), pp. 349-361.

Lin, T. T., \& Chou, J. H. (2015). Trade credit and bank loan: Evidence from Chinese firms. International Review of Economics \& Finance, v. 36, pp. 17-29.

Lousada, M., \& Valentim, M. L. P. (2011). Modelos de tomada de decisão e sua relação com a informação orgânica. Perspectivas Em Ciência Da Informação, v. 16(1), pp. 147-167.

Lukason, O., Laitinen, E. K., \& Suvas, A. (2015). Growth patterns of small manufacturing firms before failure: interconnections with financial ratios and nonfinancial variables. International Journal of Industrial Engineering and Management, v. 6(2), pp. 59-66.

Maduekwe, C. C., \& Kamala, P. (2016). The use of budgets by small and medium enterprises in Cape Metropolis, South Africa. Problems and Perspectives in Management, v. 14(1), pp. 183-191.

Marin-Idarraga, D. A., \& Cuartas-Marin, J. C. (2013). Structural Co-Alignment Influence on SMEs Performance. International Journal of Business and Management, v. 8(22), p. 76.

Martínez-Sola, C., García-Teruel, P. J., \& Martínez-Solano, P. (2014). Trade credit and SME profitability. Small Business Economics, v. 42(3), pp. 561-577.

Martins, H. H., Goes T. H. M., Shikida, P. F. A., Gimenes, R. M. T., \& Piacenti C. A. (2015). Estrutura de capital e alavancagem financeira de empresas da agroindústria canavieira: um estudo multicaso para o centro-oeste. Gestão \& Regionalidade, v. 31(93), pp. 76-93.

Maté-Sánchez-Val, M., López-Hernandez, F., \& Mur-Lacambra, J. (2017). How do neighboring peer companies influence SMEs' financial behavior? Economic Modelling, v. 63, pp. 104-114.

Matias, A. B. (2007). Finanças corporativas de curto prazo: a gestão do valor do capital de giro. São Paulo: Atlas.

Meyer Junior, V., Pascucci, L., \& Murphy, J. P. (2012). Implementing strategies in complex systems: lessons from Brazilian hospitals. BAR - Brazilian Administration Review, v. 9(spe), pp. 19-37.

Mintzberg, H. (2003). Criando organizações eficazes. 2. ed. São Paulo: Atlas.

Moreira, R. de L., Encarnação, L. V., Bispo, O. N. de A., Angotti, M., \& Colauto, R. D. (2013). A importância da informação contábil no processo de tomada de decisão nas micro e pequenas empresas. Revista Contemporânea de Contabilidade, v. 10, pp. 119-140.

Mokhtari, H. (2018). Economic order quantity for joint complementary and substitutable items. Mathematics and Computers in Simulation, v. 154, pp. 34-47.

Nascimento, R. C. (2013). Análise das metodologias aplicadas em avaliação de empresas no contexto brasileiro: um estudo sobre as ofertas públicas de aquisição (OPA). Revista de Finanças Aplicadas, v. 1(1), pp. 1-15.

Nadin, S., \& Cassell, C. (2006). The use of a research diary as a tool for reflexive practice: Some reflections from management research. Qualitative Research in Accounting \& Management, v. 3(3), pp. 208-217. 
Ngubane, N., Mayekiso, S., Sikota, S., Fitshane, S., Matsoso, M., \& Bruwer, J. (2015). Inventory management systems used by manufacturing small medium and micro enterprises in Cape Town. Mediterranean Journal of Social Sciences, v. 6(1), pp. 382-390.

Orobia, L. A., Byabashaija, W., Munene, J. C., Sejjaaka, S. K., \& Musinguzi, D. (2013). How do small business owners manage working capital in an emerging economy? A qualitative inquiry. Qualitative Research in Accounting \& Management, v. 10(2), pp. 127-143.

Panucci-Filho, L., \& Cherobin, A. P. M. S. (2011). Perspectivas Financeiras de Uma Empresa de Pequeno Porte no Curto Prazo: Um Estudo de Caso. Revista da Micro e Pequena Empresa, v. 5(2), pp. 77-90.

Patrick, M., \& French, N. (2016). The internal rate of return (IRR): projections, benchmarks and pitfalls. Journal of Property Investment \& Finance, v. 34(6), pp. 664-669.

Paula, R. M. de, Costa, D. L., \& Ferreira, M. P. (2017). A Percepção da Carga Tributária nas Micro e Pequenas Empresas antes e após o Simples Nacional. Revista da Micro e Pequena Empresa, v. 11(1), pp. 34-51.

Pillai, R. N. (2014). Factors discriminating inventory management performance: An exploratory study of Indian machine tool SMEs. Journal of Industrial Engineering and Management, v. 7(3), pp. 605-621.

Pimenta, A. M. R., \& Silva, D. R. (2017). Análise do Financiamento do Capital de Giro de Micro e Pequenas Empresas de Ituiutaba-MG. Revista da Micro e Pequena Empresa, v. 11(3), pp. 68-85.

Rahman, A., Belas, J., Kliestik, T., \& Tyll, L. (2017). Collateral requirements for SME loans: empirical evidence from the Visegrad countries. Journal of Business Economics and Management, v. 18(4), pp. 650-675.

Reis, G., Fernandes, B., \& Nakata, L. (2018). Fatores Simbólicos e Instrumentais de Atração de Pessoas em PMES Relações com o Estilo de Liderança do Empreendedor. REGEPE Revista de Empreendedorismo e Gestão de Pequenas Empresas, v. 7(2), pp. 115-144.

Rodrigues, W. C. (2014). Avaliação da maturidade de gestão de quatro unidades de proteção integral estaduais do Tocantins. REGE-Revista de Gestão, v. 21(3), pp. 325-341.

Ross, S. A., Westerfield, R. W., \& Jaffe, J. F. (2002). Administração Financeira: Corporate Finance. 2. ed. São Paulo: Atlas.

Santini, S., Favarin, E. V., Nogueira, M. A., Oliveira, M. L., \& Ruppenthal, J. E. (2015). Fatores de mortalidade em micro e pequenas empresas: um estudo na região central do Rio Grande do Sul. Revista Eletrônica de Estratégia \& Negócios, v. 8(1), pp. 145-169.

Santos, D. F. L. (2015). Modelo de Gestão Financeira Aplicada em Empresa do Setor de Construção Civil. Revista TAC, v. 5(2), pp. 119-135.

SEBRAE. (2016). Sobrevivência das Empresas no Brasil: Outubro/2016 Resumo/Apresentação. Retrieved November 13, 2018. Disponível em: <https://m.sebrae.com.br.>. Acesso em: 23 nov. 2018.

Serrasqueiro, Z., Leitão, J., \& Smallbone, D. (2018). Small-and medium-sized enterprises (SME) growth and financing sources: Before and after the financial crisis. Journal of Management and Organization, pp. 1-16. 
Vilarinho, S., Lopes, I., \& Sousa, S. (2018). Developing dashboards for SMEs to improve performance of productive equipment and processes. Journal of Industrial Information Integration, v. 12, pp. 13-22.

Vilas Boas, R. G., \& Morais, M. Í. de. (2014). Informação Contábil nas Micro e Pequenas Empresas: Uma Pesquisa de Campo na Cidade de Tangará da Serra - MT. Revista UNEMAT de Contabilidade, v. 3(6), pp. 93-117.

Vogel, J., \& Wood Jr., T. (2013). Práticas gerenciais de pequenas empresas industriais do Estado de São Paulo: um estudo exploratório. REGEPE - Revista de Empreendedorismo e Gestão de Pequenas Empresas, v. 1(2), pp. 117-140.

Yin, R. K. (2015). Estudo de Caso: Planejamento e Métodos. Porto Alegre: Bookman.

Zouain, D. M., Ferreira, C. C., Macedo, M. A. S., Sant'Anna, P. R., Longo, O. C., \& Barone, F. M. (2011). Gestão de capital de giro: contribuição para as micro e pequenas empresas no Brasil. Revista de Administração Pública, v. 45(3), pp. 863-884. 